\title{
Ecology of Haemagogus sp. and Sabethes sp. (Diptera: Culicidae) in relation to the microclimates of the Caxiuanã National Forest, Pará, Brazil
}

\author{
Claudeth S Pinto ${ }^{1 /+}$, Ulisses EC Confalonieri², Bento M Mascarenhas ${ }^{1}$ \\ Museu Paraense Emílio Goeldi, Av. Perimetral 1901, 66077-830 Belém, PA, Brasil ²Instituto de Pesquisas René Rachou-Fiocruz, \\ Belo Horizonte, MG, Brasil
}

This study was conducted in a meteorological tower located in the Caxiuanã Forest (municipality of Melgaço, Pará, Brazil) with the aim of assessing the vertical stratification of species of Haemagogus and Sabethes, potential vectors of the yellow fever virus. To investigate the role of microclimates in mosquito stratification, bimonthly collections were conducted at ground level $(0 \mathrm{~m}), 8 \mathrm{~m}, 16 \mathrm{~m}$ and $30 \mathrm{~m}$ (canopy level), with the aid of entomological nets and suction tubes, from July 2005-April 2006. A total of 25,498 mosquitoes were collected; specimens of Sabethes $s p$. and Haemagogus janthinomys were found mostly at heights of $16 \mathrm{~m}$ and $30 \mathrm{~m}$ while $\mathrm{Hg}$. leucocelaenus was most frequently observed at ground level. The largest number of vector species was collected during the rainiest months, but this difference between seasons was not statistically significant. However, the number of Hg. janthinomys was positively correlated with variations in temperature and relative humidity.

Key words: microclimate - ecology - tropical rainforest - Haemagogus - Sabethes

Culicid mosquitoes (Diptera: Culicidade) have been extensively studied in neotropical regions because of their importance in the transmission of tropical diseases such as malaria, yellow fever and dengue fever (Jones et al. 2004).

In the tropical rainforest environment, adult culicids may show vertical stratification, that is, a marked preference for different heights inside the vegetation. Some present a marked affinity for forest canopies (species termed "acrodendrophilic"), as has been reported for some species of Haemagogus and Sabethes (Roberts et al. 1981).

The patterns of activity of adult mosquitoes are influenced by endogenous biological factors as well as by reactions to the external environment, represented primarily by physical factors such as light, temperature and humidity. These factors directly influence the distribution of these insects (De Kruijf et al. 1973).

Pittendrigh (1950) regarded microclimates and host stratification (food sources) as the main determinants of the ecological niches of culicid species in tropical forests.

In the Amazon Forest there are important differences in the microclimates at different vertical strata, such as the canopy and the understorey; the latter receives only $2 \%$ of the total amount of light that reaches the canopy (Whitmore 1998). This has a marked influence on the temperature and the relative humidity $(\mathrm{RH})$ in various forest strata (Lines 1993).

Financial support: Interamerican Institute for Global Change Research (CRN 048)

+ Corresponding author: dethsp@yahoo.com.br

Received 15 November 2008

Accepted 22 June 2009
Another important factor that regulates the population distribution of mosquitoes is precipitation, which is extremely variable between the different regions (Wolda \& Galindo 1981). In the tropics, water in breeding sites has to rise to a critical level in order to reach the mosquito eggs, which hatch a few days after this contact; therefore, the number of culicid mosquitoes is often directly associated with the amount of rainfall (De Kruijf 1970, Souto 1994, Rocha et al. 1997, Guimarães et al. 2001, Montes 2005).

Although several studies on the stratification of culicids have been published, few of them have investigated the role of climatic factors as determinants of the vertical distribution of these mosquitoes. Understanding the vertical stratification of culicid mosquitoes, which may act as vectors of arboviral diseases in the tropical forest and the role of microclimatic factors in this process, is important for an assessment of disease risks in the natural environment.

The current study analysed the distribution of neotropical mosquito species of the genera Haemagogus and $\mathrm{Sa}$ bethes in one site of the Amazon upland forest and assessed the role played by climatic factors in their distribution.

\section{MATERIALS AND METHODS}

The field work was undertaken at the National Caxiuanã Forest, located in the municipality of Melgaço, state of Pará, Brazil (eastern Amazon Region) (Fig. 1). Mosquito collections were conducted in the meteorological tower of the Project for Large-Scale Biosphere-Atmosphere Experiments in the Amazon (LBA-Carbo, PA), administered by the Ferreira Pena Scientific Station of the Emilio Goeldi Museum (Brazilian Ministry of Science and Technology). The tower is located at the coordinates $01^{\circ} 43^{\prime} 9.9^{\prime \prime} \mathrm{S} 51^{\circ} 27^{\prime} 31.4^{\prime \prime} \mathrm{W}$; it is $54 \mathrm{~m}$ high and has equipments for the measurement of several physical processes. 

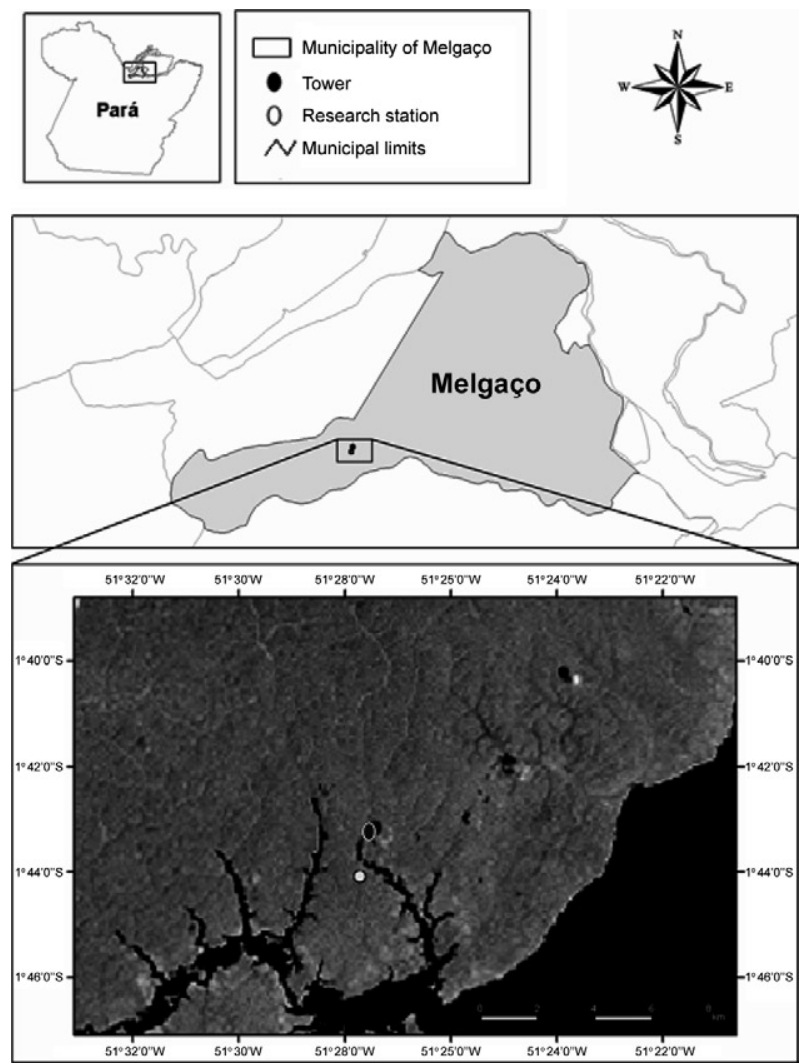

Fig.1: location of the micro-meteorological tower where the collections were made (image provided by the Spatial Analysis Unit of the Emilio Goeldi Museum).

The Caxiuanã National Forest has a vegetation cover composed of four main types of systems: dense forest in the low plateaus (terra firme), representing $80-85 \%$ of the area; periodically inundated floodplain forest; permanently inundated Igapó forests; and natural fields, where grass is the dominant type of vegetation (Lisboa 2002).

The climate in Caxiuanã is tropical humid and the rainiest season (monthly average of $252 \mathrm{~mm}$ ) runs from January through June; from July through December, the monthly average rainfall is $55 \mathrm{~mm}$. The annual average temperature is around $26^{\circ} \mathrm{C}$; the lowest temperature occurs from January-March, averaging $26^{\circ} \mathrm{C}$ and the hottest period is from October-December, with an average above $27^{\circ} \mathrm{C}$. The average RH is around 88\% (Lisboa \& Ferraz 1999).

Data were collected during five field trips, in the months of July, September and December 2005 and February and April 2006. Each field trip included three night-time and two diurnal collecting periods lasting $12 \mathrm{~h}$ each. Mosquito captures were conducted using hand nets and CDC traps, at four different heights in the tower: 30 $\mathrm{m}$ (forest canopy), $16 \mathrm{~m}, 8 \mathrm{~m}$ and ground level $(0 \mathrm{~m})$. The collections took place from 6:00 am-6:00 pm (daytime collections) and from 6:00 pm-6:00 am (night-time collections). One collector and one CDC trap were placed at each height; after every $12 \mathrm{~h}$ period of capture, each person moved to a different height in order to minimise personal bias. Specimens were identified at the zoology laboratory of the Ferreira Pena Scientific Station, with the aid of the identification keys provided by Consoli and Lourenço-de-Oliveira (1994) and Forattini (2002).

Microclimatic measurements were taken continuously and automatically and data were stored in the tower's datalogger.

Statistical tests were applied to analyse the seasonal variation of the species and their population densities as well as the time of activity of the adult mosquitoes in relation to the variation in rainfall, temperature and humidity.

The key species of mosquito studied because they are potential vectors of yellow fever were Haemagogus janthinomys, Haemagogus leucocelaenus and Sabethes chloropterus. Comparisons were made with the ANOVA test (number of specimens of each species at different heights and times of the day). For the comparison of averages, Tukey's test ( 0.05 probability) was used, with the aid of the software Estat (Universidade Estadual Paulista, São Paulo, Brazil).

Linear regression and the chi-square test were used to analyse the association between height and the numbers of Hg. Janthinomys, Sa. chloropterus and Hg. leucocelaenus; correlation analyses to determine whether there is an association between the number of vectors and environmental factors (temperature and humidity) were done with the software Biostat 4.0.

\section{RESULTS}

From July 2005-April 2006, a total of 25,498 specimens of adult culicids were obtained during night-time and daytime collections.

Daytime captures yielded 1,530 specimens of species considered to be potential vectors of sylvatic yellow fever: 1,028 belonged to the genus Haemagogus and 502 to the genus Sabethes. Specimens of these two genera were not found during the night-time collections. Two species of the genus Haemagogus - Hg. janthinomys and Hg. leucocelaenus - as well as eight species of Sabethes were found during the daytime collections (Table I).

Vertical distribution - Hg. janthinomys and all $\mathrm{Sa}$ bethes sp. were found mostly at or close to the forest canopy while $\mathrm{Hg}$. leucocelaenus was more common at ground level. The largest number of specimens of $S a$. chloropterus was found at $16 \mathrm{~m}$; Hg. janthinomys and Sabethes belisarioi were predominant at $30 \mathrm{~m}$ (Table I). Height was shown to influence the number of $\mathrm{Hg}$. janthinomys, Hg. leucocelaenus and Sa. chloropterus $\left(\mathrm{X}^{2}=\right.$ 664.89; $\mathrm{p}<0.0005$ ).

About $90 \%$ of the specimens of $\mathrm{Hg}$. janthinomys were found at $16 \mathrm{~m}$ and $30 \mathrm{~m}$; only $1 \%$ were obtained on the ground. Fifty-four percent of specimens of $\mathrm{Hg}$. leucocelaenus were collected at $30 \mathrm{~m}$ and only $5 \%$ at the canopy level. Sabethes glaucodaemon and Sa. cholopterus were not found at ground level and just one specimen of Sabethes cyaneus was found at ground level (0 m) (Figs 2,3).

Monthly variation - The greatest abundance of $\mathrm{Hg}$. janthinomys occurred in February and Hg. leucocelaenus was most frequent in the months of July and September. Sa. chloropterus was more frequently captured in 


\section{TABLE I}

Number of specimens of Haemagogus and Sabethes collected by height, from July 2005-April 2006

\begin{tabular}{|c|c|c|c|c|c|c|}
\hline \multirow[b]{2}{*}{ Genus } & \multirow[b]{2}{*}{ Species } & \multicolumn{5}{|c|}{$\begin{array}{l}\text { Height } \\
\text { m }\end{array}$} \\
\hline & & 0 & 8 & 16 & 30 & total \\
\hline \multirow[t]{6}{*}{ Haemagogus } & Hg. janthinomys ${ }^{a}$ & 8 & 59 & 377 & 409 & 853 \\
\hline & Hg. leucocelaenus ${ }^{a}$ & 96 & 27 & 44 & 8 & 175 \\
\hline & Sa. amazonicus & 0 & 1 & 1 & 17 & 19 \\
\hline & Sa. belisarioi ${ }^{a}$ & 0 & 1 & 6 & 37 & 44 \\
\hline & Sa.chloropterus ${ }^{a}$ & 0 & 16 & 168 & 87 & 271 \\
\hline & Sa. cyaneus ${ }^{a}$ & 1 & 24 & 38 & 27 & 90 \\
\hline \multirow[t]{4}{*}{ Sabethes } & Sa.forattini & 0 & 0 & 0 & 9 & 9 \\
\hline & Sa. glaucodaemon ${ }^{a}$ & 0 & 2 & 22 & 18 & 42 \\
\hline & Sa. quasicyaneus & 0 & 0 & 0 & 1 & 1 \\
\hline & Sa. tarsopus & 0 & 0 & 1 & 25 & 26 \\
\hline Total & & 105 & 130 & 657 & 638 & 1530 \\
\hline
\end{tabular}

$a$ : species associated with the transmission of the yellow fever virus.

July and February while Sa. cyaneus and Sa. belisarioi were more abundant in February; the largest number of Sa. glaucodaemon was found in April (Fig. 4).

In the months of July and September 2005, Hg. janthinomys and $\mathrm{Sa}$. chloropterus were captured in largest numbers at a height of $16 \mathrm{~m}$. Hg. janthinomys and $\mathrm{Sa}$. chloropterus were found mostly at $16 \mathrm{~m}$ in December, a period during which neither Haemagogus nor Sabethes were found at ground level.

In February and April 2006 (rainy period), a gradual increase in the number of $\mathrm{Hg}$. janthinomys captured was found with increasing height. This species was more abundant in the month of February.

Statistical analysis was carried out by month of collection. In every month of the study period, the samples behaved the same way for $\mathrm{Hg}$. janthinomys, Hg. leucocelaenus and Sa. chloropterus; the variable heights had a statistically significant influence on the number of specimens collected per species (July $\mathrm{X}^{2}=166.58, \mathrm{p}<$ 0.0001 ; September $X^{2}=33.47, p<0.0001$; December $X^{2}$ $=51.55, \mathrm{p}<0.0001$; February $\mathrm{X}^{2}=346.98, \mathrm{p}<0.0001$; April $\left.\mathrm{X}^{2}=71.33, \mathrm{p}<0.0001\right)$.

Circadian activity - The host-seeking activity of the mosquitoes started at 6:00 am. Both for $\mathrm{Hg}$. janthinomys and for the species of the genus Sabethes (Sa. chloropterus, Sa. cyaneus, Sa. glaucodaemon and Sa. belisarioi), two marked peaks of activity were observed: one from 12:00-1:00 pm and the other between 3:00-4:00 pm. $\mathrm{Hg}$. leucocelaenus was more active between 2:00-3:00 pm.

For all species of both genera, a decrease was observed in the number of specimens collected after 4:00 $\mathrm{pm}$ and specimens were captured in very low numbers at 6:00 pm (Fig. 5).

Climatic data - The highest average temperature $\left(26.09^{\circ} \mathrm{C}\right)$ was observed in December 2005 and the low-
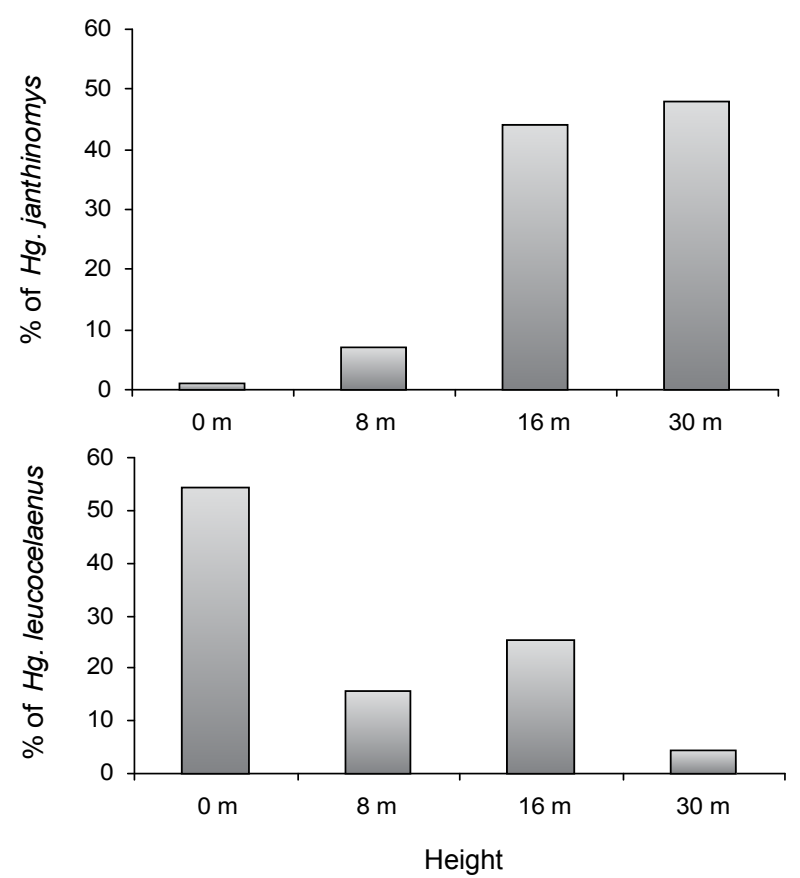

Fig. 2: relative abundances of Haemagogus janthinomys and Haemagogus leucocelaenus collected in four different heights at the Caxiuanã Forest (from July 2005-to April 2006).

est in April $2006\left(23.45^{\circ} \mathrm{C}\right)$. In the months of July 2005, September 2005 and April 2006, the highest temperatures were recorded at $16 \mathrm{~m}$ and the lowest at ground level. In December 2005, the highest temperature was recorded at $30 \mathrm{~m}$ and the lowest at $8 \mathrm{~m}$. The highest $\mathrm{RH}$ was recorded in February 2006 (average 92.02\%) and the lowest occurred in December 2005 (76.55\%). In September 2005 and April 2006, the highest values for RH occurred at ground level and the lowest at $30 \mathrm{~m}$; in December 2005, the lowest RH value was found at $30 \mathrm{~m}$ and the highest temperature was at $8 \mathrm{~m}$ (Table II).

The rainiest period was the month of January 2006 and the driest was October 2005. This difference in precipitation influenced the number of mosquitoes collected; they were more frequently observed in the month following the rainiest period and the lowest number of captures also followed the driest month.

Statistical analysis - No statistical difference was found in the number of specimens of $\mathrm{Hg}$. janthinomys, Hg. leucocelaenus and Sa. chloropterus collected in the different months; however, a significant difference was found in the number of Sa. chloropterus specimens collected at the four heights.

In the comparison of average distribution of $\mathrm{Hg}$. janthinomys at the four different heights, no statistical significance was found using Tukey's test ( 0.05 probability); the same was observed for $\mathrm{Hg}$. leucocelaenus. However, for $\mathrm{Sa}$. chloropterus, a statistically significant difference was found between the heights $16 \mathrm{~m}$ vs. $8 \mathrm{~m}$ and $16 \mathrm{~m}$ vs. $0 \mathrm{~m}$. No statistically significant difference was found between $16-30 \mathrm{~m}$ or between $0-8 \mathrm{~m}$ and $30 \mathrm{~m}$. According to 

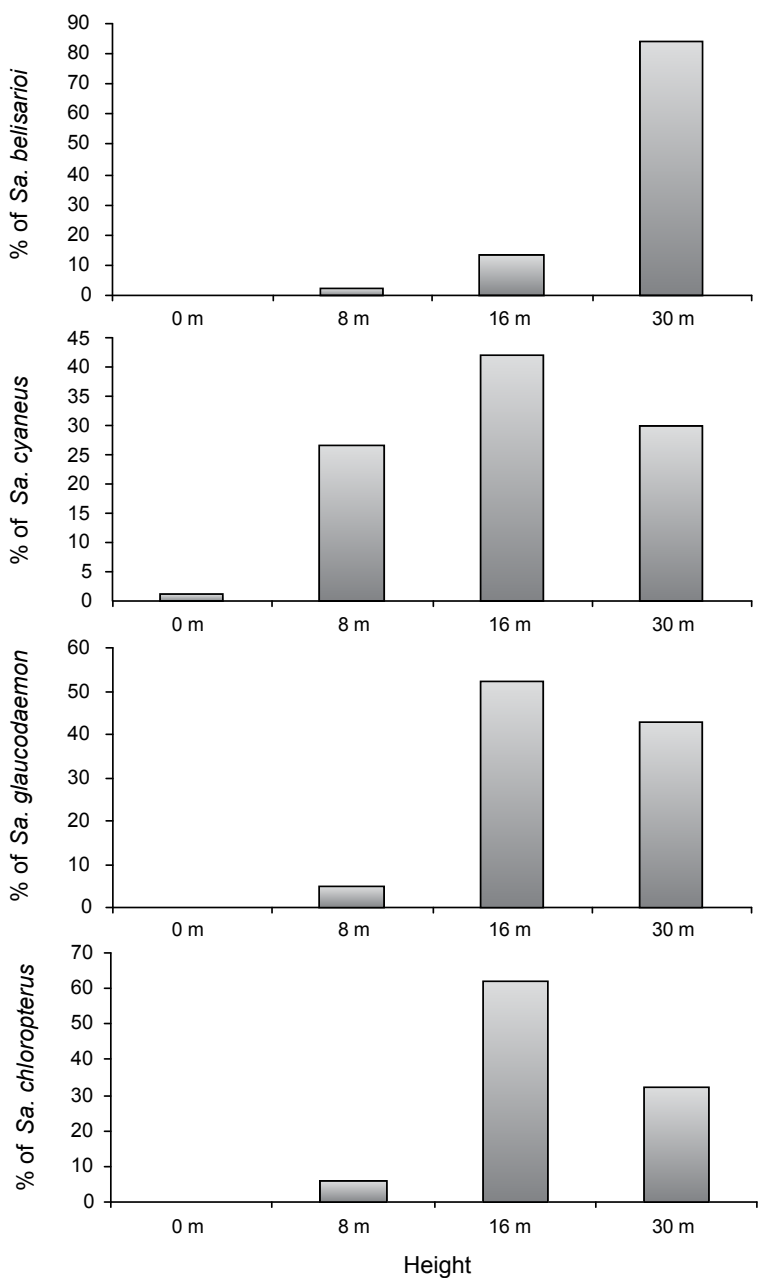

Fig. 3: relative abundances of species of Sabethes collected in four different heights at the Caxiuanã Forest (from July 2005-April 2006).

Tukey's test ( 0.05 probability), there was no statistically significant difference in the average distributions in the different months of collection, at all heights.

In the linear regression tests, it was observed that height had a direct relationship with the number of $\mathrm{Hg}$. janthinomys $\left(\mathrm{y}=14.783 \mathrm{x}+13.678 ; \mathrm{R}^{2}=0.82\right)$ and $S a$. chloropterus $\left(\mathrm{y}=3.595 \mathrm{x}+18.971 ; \mathrm{R}^{2}=0.36\right)$. On the other hand, an inverse relationship was found for $\mathrm{Hg}$. leucocelaenus $\left(\mathrm{y}=-2.394 \mathrm{x}+75.57 ; \mathrm{R}^{2}=0.69\right)$.

Temperature was not correlated with the number of Hg. leucocelaenus $(\mathrm{p}=0.117)$ or $S a$. chloropterus $(\mathrm{p}=$ 0.09 ) at the different heights of collection, but there was an association between temperature and the abundance of $H g$. janthinomys $(\mathrm{p}=0.03)$ at different heights.

The RH of the air was correlated with the abundance of Hg. janthinomys $(\mathrm{p}=0.009)$ but was not correlated with the distribution of Hg. leucocelaenus ( $\mathrm{p}=0.50$ ) or $\mathrm{Sa}$. chloropterus $(\mathrm{p}=0.056)$ at the different heights considered.

\section{DISCUSSION}

Mondet et al. (2002), Ferreira Fé et al. (2003) and Ramírez et al. (2007) observed that $H g$. janthinomys adults were more commonly found in forest canopies.

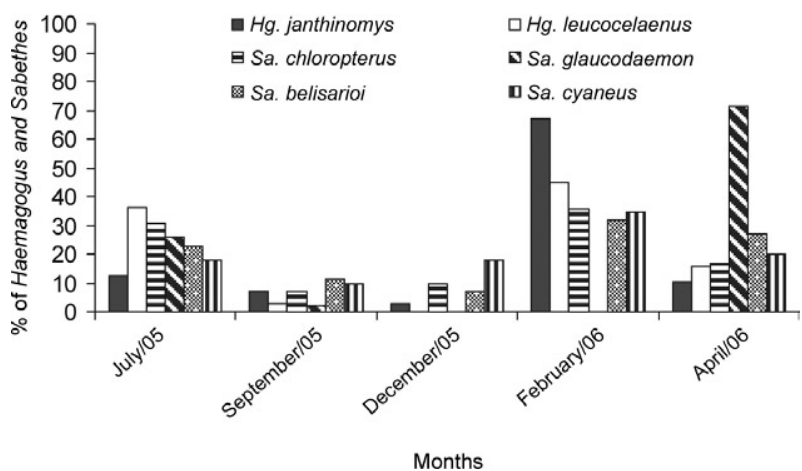

Fig. 4: relative monthly abundances of each species of Haemagogus and Sabethes, captured in the study area from July 2005-April 2006.

This same preference for the higher strata of the forest was also observed in our Caxiuanã Forest study, although a few specimens were also found at ground level. According to Galindo et al. (1956), the movement of canopy mosquitoes towards the ground is common in deciduous forests but rare in humid forests. Sabethes species, like $\mathrm{Hg}$. janthinomys, were classified in our study as "acrodendrophilic". Sa. belisarioi had $80 \%$ of its specimens collected at a height of $30 \mathrm{~m}$, a fact also observed by Mondet et al. (2002) and Rocha et al. (1997) in the studies undertaken at Belém and Caxiuanã, respectively, both in PA.

Roberts et al. (1981) observed that, around the Transamazon Highway (PA, Brazil), Hg. janthinomys and species of Sabethes were more abundant at the canopy level while $\mathrm{Hg}$. leucocelaenus was homogeneously distributed between the canopy and the ground. At Caxiuanã, $H g$. leucocelaenus was collected in higher numbers on the ground, which corroborates the observations made by Mondet (2002). However, this was not observed by Ferreira Fé et al. (2003), who collected a larger number of specimens of this species at the canopy level.

Although most of the specimens of Sabethes and Haemagogus in our study were found at the canopy level, some specimens were also captured on the ground in numbers varying according to the time of the day and the month of the year, as a response to variations in temperature and humidity.

The circadian activity of mosquito vectors may be related to the resting periods of their hosts (MachadoAlison 1982). Chadee (1990) observed a more aggressive behaviour of $\mathrm{Hg}$. janthinomys and Sa. chloropterus females towards their hosts between the late morning hours and the early afternoon, a period of the day corresponding to the resting time of monkeys, their preferred hosts. This author has collected specimens of Sa. chloropterus between 6:00-8:00 pm. In Caxiuanã, our nighttime collections (after 6:00 pm) did not detect the activity of Sabethes or Haemagogus, a fact also observed by Roberts et al. (1981) and Rocha et al. (1997).

Kumm and Novis (1938), in a field study conducted at Curralinho, Marajó Island (PA) and Rocha et al. (1997), in a study at Caxiuanã, reported two distinct peaks of blood-feeding activity for $\mathrm{Hg}$. janthinomys: the first, more intense, between 12:00-1:00 pm, and the second, 
TABLE II

Temperature and average humidity. measured from July 2005-April 2006. at the ground and in platforms at $8 \mathrm{~m} .16 \mathrm{~m}$ and $30 \mathrm{~m}$ in the micrometeorological tower

\begin{tabular}{|c|c|c|c|c|c|c|c|c|c|c|}
\hline \multirow[b]{2}{*}{ Months } & \multicolumn{5}{|c|}{$\begin{array}{c}\text { Temperature } \\
{ }^{\circ} \mathrm{C}\end{array}$} & \multicolumn{5}{|c|}{$\begin{array}{c}\text { Humidity } \\
\%\end{array}$} \\
\hline & Ground & $8 \mathrm{~m}$ & $16 \mathrm{~m}$ & $30 \mathrm{~m}$ & Average & Ground & $8 \mathrm{~m}$ & $16 \mathrm{~m}$ & $30 \mathrm{~m}$ & Average \\
\hline $\mathrm{Jul} / 05$ & 23.28 & 26.78 & 27.14 & 26.78 & 25.99 & 90.44 & 83.72 & 77.91 & 76.70 & 82.19 \\
\hline Sep/05 & 23.51 & 27.11 & 27.44 & 25.52 & 25.89 & 87.39 & 80.25 & 73.73 & 72.33 & 78.42 \\
\hline Dec/05 & 25.75 & 25.36 & 26.36 & 26.89 & 26.09 & 77.92 & 80.77 & 75.29 & 72.23 & 76.55 \\
\hline Feb/06 & 24.75 & 25.23 & 25.38 & 23.88 & 24.81 & 99.96 & 91.91 & 87.40 & 88.82 & 92.02 \\
\hline Apr/06 & 22.22 & 23.47 & 24.43 & 23.67 & 23.45 & 93.46 & 91.36 & 89.62 & 86.31 & 90.19 \\
\hline
\end{tabular}

less pronounced, in the time interval between 3:00-4:00 pm. This same pattern was observed in our study, both for Hg. janthinomys and for Sa. chloropterus, Sa. cyaneus, Sa. galucodaemon and Sa. belisarioi. In Suriname and Guyana, De Kruijf (1970) observed a unimodal peak for the activity of $\mathrm{Hg}$. janthinomys, with most activity taking place by midday. In our Caxiuanã study, this species had a bimodal peak of activity.

Environmental characteristics such as temperature and RH vary greatly between the canopy and understorey levels of the tropical forest (Parker 1995). This variation can influence the distribution of plants and animals, including mosquitoes (Pittendrigh 1950). These parameters can vary according to the structure of the forest and the abundance and duration of rainfall (Madigosky \& Vatnick 2000).
Puig (2000) states that the forest canopy acts as a buffer with regard to the temperature and humidity of the atmosphere above the forest. He also stresses that the daily thermal amplitude in the forest is much larger in the canopy then at ground level. This variation is greater on sunny days than on days with overcast weather; the $\mathrm{RH}$ at $1 \mathrm{~m}$ above the ground on dry days is similar to that of the canopy on humid days (Puig 2000).

In the Peruvian Amazon, Ramírez et al. (2007) found higher temperatures at the canopy when compared to the understorey. In our study, the highest temperatures were observed at $16 \mathrm{~m}$ in all months of collection, except in December, when the highest temperature was found at $30 \mathrm{~m}$. Ramírez et al. (2007) did not find a correlation between the abundance of $\mathrm{Hg}$. janthinomys and the
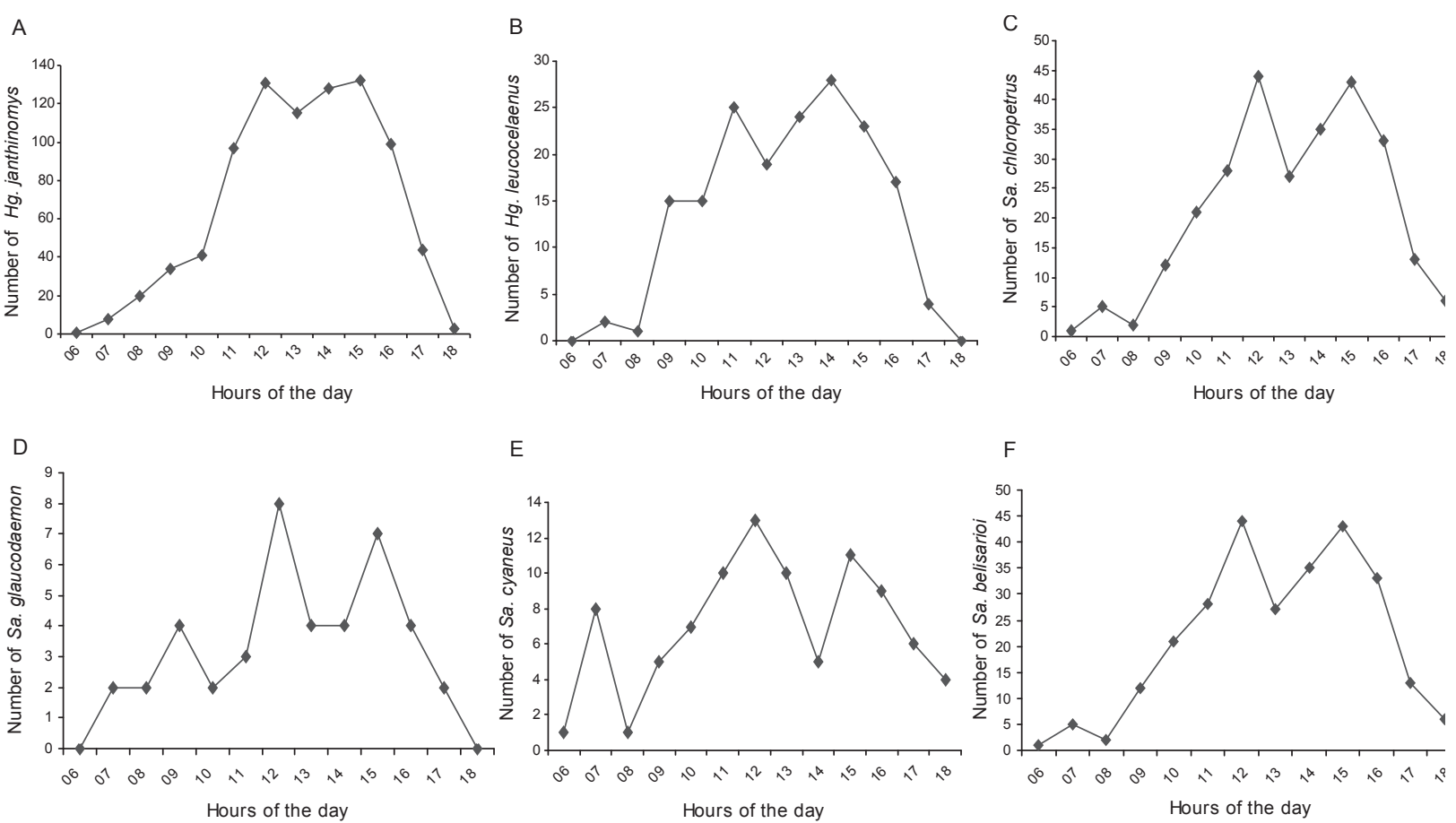

Fig. 5: number of specimens collected at each hour, from July 2005-April 2006, for the following species: Hg. janthinomys (A); Hg. leucocelaenus (B); Sa. chloropterus (C); Sa. glaucodaemon (D); Sa. cyaneus (E) and Sa. belisarioi (F). 
variation in temperature and RH. Our study did observe a correlation between the variation in the number of Hg. janthinomys collected and temperature at different heights; however, this correlation was not observed for Hg. leucocelaenus or Sa. chloropterus. A correlation was also found between the RH and the number of $H g$. janthinomys at different heights, but there was no such correlation for Sa. chloropterus and Hg. leucocelaenus.

Rainfall can influence mosquito populations by either decreasing or increasing them. Usually, in the wet tropics, epizootics and epidemics of mosquito-borne diseases are associated with the onset of the rainy season, when the population densities of vectors are higher. For example, in the case of yellow fever, it is important for an adequate assessment of the risk of transmission to analyse the linkage between the vector population density and the variation of climatic factors, especially rainfall (Dégallier 2006). De Kruijf et al. (1973) observed variable correlations between the intensity of rainfall and the number of mosquitoes, according to the different species. In Caxiuanã, we observed that the rainiest months influence yellow fever vector species since the population densities of these mosquitoes usually increased in the months during or following a rainy period.

In other vertical distribution studies conducted by Guimarães and Arlé (1984), a larger number of Sabethes sp. were observed in the month of January and, for $\mathrm{Hg}$. leucocelaenus, population peaks were observed in November and June; $90 \%$ of the specimens of $\mathrm{Hg}$. janthinomys were collected in December.

In the present study, Hg. janthinomys was more abundant in February at all heights, but Hg. leucocelaenus was more common in July and February at heights of 8 $\mathrm{m}, 16 \mathrm{~m}$ and $30 \mathrm{~m}$. Hg. leucocelaenus was not collected at ground level during these months.

Rocha et al. (1997) also observed in Caxiuanã that the number of culicid mosquitoes was larger during the rainy season and that the population decreased at the start of the dry season, both at canopy and ground level. They also found that the number of Hg. janthinomys was greater at the canopy level both in June and in February. During these months, the species dominating at ground level was Hg. leucocelaenus. However, although specimens of Haemagogus were more frequent in rainy months, the statistical correlation was not significant. The authors also observed that the numbers of Sa. chloropterus and Sa. glaucodaemon were positively correlated with rainfall and negatively correlated with temperature.

In the current study, the rainiest month was February; the increase in rainfall had an effect on the number of mosquitoes collected in the following weeks. The largest number of $\mathrm{Hg}$. janthinomys was observed in February and $\mathrm{Hg}$. leucocelaenus and S. chloropterus were more frequent in both February and April. Although we empirically observed that the number of the most important potential yellow fever vector species $-H g$. janthinomys, Hg. leucocelaenus and Sa. chloropterus - increased during and soon after the periods of more intense rainfall, this variation was not statistically significant.
It is important to stress that, besides the influence of the abiotic variables studied here, other physical factors such as light - which varies significantly between the closed canopy of tropical forests and the understorey and the habits of the vertebrate hosts of mosquitoes (e.g., resting periods) may also have an effect on the stratification of the vector species as well as on their peak hours of blood-sucking activity.

\section{REFERENCES}

Chadee DE 1990. Seasonal abundance and diel landing periodicity of Sabethes chloropterus (Diptera: Cuicidae) in Trinidad, West Indies. J Med Entomol 27: 1041-1044.

Consoli RAG, Lourenço-de-Oliveira R 1994. Principais mosquitos de importância sanitária no Brasil, Editora Fiocruz, Rio de Janeiro, $225 \mathrm{pp}$.

De Kruijf HAM 1970. Aspects of the ecology of mosquitoes in relation to the transmission of arboviruses in Surinam, Dissertation, Leiden University, Leiden, 100 pp.

De Kruijf HAM, Woodall JP, Tang AT 1973. The influence of accumulated rainfall and its pattern on mosquito (Diptera) populations in Brazil. Bull Entomol Res 63: 327-333.

Dégallier N, Monteiro HAO, Castro FC, Silva OV, Sá Filho GC, Elguero E 2006. An indirect estimation of the developmental time of Haemagogus janthinomys (Diptera: Culicidae), the main vector of yellow fever in South America. Stud Neotropical Fauna Environ 41: 117-122.

Ferreira Fé N, Barbosa MGV, Fé FA, Guerra MVF, Alecrim WD 2003. Fauna de Culicidae em municípios da zona rural do estado do Amazonas, com incidência de febre amarela. Rev Soc Bras Med Trop 36: 343-348.

Forattini OP 2002. Culicidologia médica. Identificação, biologia, epidemiologia, Vol.2, Edusp, São Paulo, 860 pp.

Galindo P, Trapido H, Carpenter SJ, Blanton FS 1956. The abundance cycles of arboreal mosquitoes during six years at a sylvan yellow fever locality in Panama. Ann Entomol Soc Am 49: 543:547.

Guimarães EA, Arlé M 1984. Mosquitos no Parque Nacional da Serra dos Órgãos, Estado do Rio de Janeiro, Brasil. I. Distribuição estacional. Mem Inst Oswaldo Cruz 79: 309-323.

Guimarães AE, Gentile C, Lopes CM, Sant'anna A 2001. Ecologia de mosquitos em áreas do Parque Nacional da Serra da Bocaina. II: Freqüência mensal e fatores climáticos. Rev Saude Publica 35: 392-399.

Jones J W, Turell MJ, Sardelis MR, Watts DM, Coleman RE, Fernandez R, Carbajal F, Pecor JE, Calampa C, Klein TA 2004. Seasonal distribution, biology and human attraction patterns of Culicinae mosquitoes (Diptera: Culicidae) in a forest near Puerto Almendras, Iquitos, Peru. J Med Entomol 41: 349-360.

Kumm HW, Novis O 1938. Mosquito studies in the Ilha do Marajó, Pará, Brazil. Am Trop J Hyg 27: 498-515.

Lines J 1993. The effects of climatic and land-use changes on insect vectors of human disease. In Insects in a changing environment, 17th Symposium of the Royal Entomological Society of London, 7-10 September.

Lisboa PLB 2002. Natureza, homem e manejo de recursos naturais na região de Caxiuanã, Melgaço, Pará, Museu Paraense Emílio Goeldi, Belém, $237 \mathrm{p}$.

Lisboa PLB, Ferraz MG 1999. Estação Científica Ferreira Penna: ciência e desenvolvimento sustentável na Amazônia, Museu Paraense Emílio Goeldi, Belém, 151 pp. 
Machado-Alison CE 1982. Ecologia de los Mosquito (Culicidae). III. Adultos. Acta Biol Venez 11: 133-237.

Madigosky SR, Vatnick I 2000. Microclimatic characteristics of a primary tropical Amazonian rain forest, ACEER, Iquitos, Peru. Selbyana: 21: 165-172.

Mondet B, Freitas NM, Travassos da Rosa APA, Vasconcelos PFC, Vieira CMA 2002. Biologia dos culicídeos vetores da febre amarela. In PLB Lisboa (org.), Caxiuanã. Populações tradicionais, meio fisico e diversidade biológica, Museu Paraense Emílio Goeldi, Belém, p. 589-598.

Montes J 2005. Fauna de Culicidae da Serra da Cantareira, São Paulo, Brasil. Rev Saude Publica 39: 578-584.

Parker GG 1995. Structure and microclimate of forest canopies. In MD Lowman, NM Nadkarni (eds), Forest canopies, Academic Press, San Diego, p. 73-106.

Pittendrigh CS 1950. The ecoclimatic divergence of Anopheles bellator and An. homunculus. Evolution 4: 43-63.

Puig H 2000. La forêt tropicale humide, Cap. 2, Belin, Paris, p. 45-74.
Ramírez JRP, Yanoviak SP, Lounibos LP, Weaver SC 2007. Distribución vertical de Haemagogus janthinomys (Dyar) (Diptera: Culicidae) en bosques de La Amazonía Peruana. Rev Peru Med Exp Salud Publica 24: 40-45.

Roberts DR, Hoch AL, Peterson NE, Pinheiro FP 1981. Programa multidisciplinar de vigilancia de las enfermedades infecciosas em zonas colindantes com la carretera transamazônica em Brasil. IV. Estudios entomológicos. Bol Ofic Sanit Panam 91: 379-400.

Rocha JAM, Mascarenhas BM, Barata JMS 1997. Os mosquitos (Diptera: Culicidae). In PLB Lisboa (org.), Caxiuanã, Museu Paraense Emilio Goeldi, Belém, p. 335-345.

Souto RNP 1994. Sazonalidade de culicídeos (Diptera: Culicidae) e tentativa de isolamento de arbovírus em floresta e savana no estado do Amapá, Dissertação de Mestrado, Museu Paraense Emílio Goeldi, Universidade Federal do Pará, 99 pp.

Whitmore TC 1998. An introduction to tropical rain forests, 2nd ed., Oxford University Press, Oxford, $282 \mathrm{pp}$.

Wolda H, Galindo P 1981. Population fluctuations of mosquitoes in the non-seasonal tropics. Ecol Entomol 6: 99-106. 